\title{
CONCEPÇÕES ACERCA DA AVALIAÇÃO DA APRENDIZAGEM
}

\author{
Maria Luiza Figueredo de Araújo ${ }^{1}$
} Marlucia da Silva Ribeiro ${ }^{2}$

\section{RESUMO}

O objetivo desse artigo é, apresentar uma breve contextualização das concepções de avaliação da aprendizagem. A metodologia utilizada foi a revisão biográfica, pois partiu-se dos estudos já publicados de autores renomados na área como Vasconcelos (2000; 2011; 1998); Perrenoud (1999); Luckesi $(2005 ; 2002 ; 2011)$ e outros. Conclui-se que pensar e trazer à tona das concepções de avaliação da aprendizagem, no contexto escolar e nas ações pedagógicas cotidianas do professor em sala de aula, requer refletir o verdadeiro papel desta na prática docente. Nesse contexto, avaliar vai muito além da realização das provas e testes, pois é um processo contínuo e que ocorre dia após dia, diagnosticando e intervindo na melhoria dos resultados do educando, buscando o melhor e mais satisfatório estado do que está sendo avaliado. Portanto, avaliação é um ato que deve incluir o educando, acontecendo de forma dinâmica e construtiva, funcionando como um elemento de integração e motivação para o processo de ensino-aprendizagem.

Palavras-chaves: Avaliação da aprendizagem. Concepções. Avaliação Formativa.

\section{RESUMEN}

El objetivo del artículo es, a continuación, una breve contextualización de las concepciones de la situación del aprendizaje. Una metodología para una revisión biográfica, se publicó dos veces más allá de los autores de los autores en un área como Vasconcelos (2000; 2011; 1998); Perrenoud (1999); Luckesi $(2005 ; 2002 ; 2011)$ e outros. Concluirá el tema de pensar y trazar las ideas de las prácticas de aprendizaje, el contexto escolar y las actividades pedagógicas cotidianas del profesor en la sala de aula, que requieren un papel o documento sobre la prática docente. Contexto de Nesse, avaliar vai muito além da la realización de las pruebas y los resultados, el proceso y el proceso de seguimiento y el diagnóstico, diagnóstico e intervención en los resultados de los resultados de la educación, la búsqueda de resultados y la satisfacción de los resultados. Portanto, avaliação é um toto que tove to to include to education, eventecendo of forme dinâmica and construtiva, as is as element of integração and motivação for o processo of ensino-aprendizagem.

Palavras-chaves: Avaliação da aprendizagem. Concepciones Avaliação Formativa.

\section{INTRODUÇÃO}

A avaliação da aprendizagem tem sido um aspecto problemático na prática pedagógica. Para o professor, o grande dilema da avaliação está centrado no aproveitamento escolar, em como decidir se o aluno passa ou não

\footnotetext{
${ }^{1}$ Mestra em Ciências da Educação pela Faculdade Interamericana de Ciências Sociais (FICS). Licenciada em Matemática pela Faculdade Jorge Amado. Especialista em Metodologia do Ensino Superior pelo Centro Universitário da Bahia (FIB). Especialista em Metodologia do Ensino da Matemática pelo Instituto Superior de Educação Afonso Cláudio (ISEAC). E-mail: luizafigueredoaraujo@hotmail.com

${ }^{2}$ Mestra em Ciências da Educação pela Faculdade Interamericana de Ciências Sociais (FICS). Licenciada em História pela Universidade Católica de Salvador (UCSal); Especialista em Metodologia Pesquisa e Extensão pela Universidade do Estado da Bahia (UNEB) Especialista em Avaliação pela Universidade do Estado da Bahia (UNEB) Funcionária Pública do Estado da Bahia e Prefeitura Municipal de Salvador E-mail:ribeiromarlucia89@gmail.com
} 
de série, uma decisão que pode influenciar muito na vida do aluno e aumentar não somente os índices de repetência, mas também os de evasão escolar. Faz-se necessário refletir sobre o seu papel, bem como das condições necessárias para que esta se efetue de maneira justa e coerente. Muitos professores não sabem como avaliar, e a prova acaba se transformando em um processo de cobrança dos conteúdos aprendidos ou decorados pelos alunos, ou ainda em vingança (LUCKESI, 2011)

Essa foi historicamente associada a escola numa perspectiva tradicional, construindo assim, hierarquias e valorizando arbitrariamente a individualidade, a classificação e a competição entre os alunos. Atrelado a essa visão, observa-se desigualdades de êxito, limitando-se a oferecer aos alunos a oportunidade de aprender de maneira mecânica e excludente, pois nem todos apresentam as mesmas competências e habilidades ao longo do processo avaliativo (LUCKESI, 2011).

A avaliação tradicional, que se encerra na nota através de instrumentos avaliativos como teste e provas estiveram presentes nas escolas por um longo período, como único modelo adotado nas unidades escolares. O professor preparava o aluno para em uma semana de prova expor todos os seus conhecimentos. Hoje, as escolas se dizem inovadoras, por sua vez, cometem grandes equívocos, ainda sim, estão preocupadas apenas em notas, mesmo apresentando diversidade de atividades, o que em certa medida, ampliam o leque de instrumentos, mas ainda sim, ao final de um processo são somadas, gerando notas, o que acabam por excluir e classificar, aqueles que não atenderam as demandas (HOFFMAN, 2001).

Diversificar as atividades não significa nova concepção de avaliação. É preciso compreender que não adianta realizar inúmeras atividades se utilizando de um processo somatório, visto que não são formas ou procedimentos préfixados ou instrumentos variados que vão resolver os problemas da avaliação isto é, da aprendizagem. Portanto nem todo processo avaliativo configura-se em procedimentos formativos.

Para tanto, esse estudo levanta o seguinte problema: quais são as concepções adotadas acerca da avaliação da aprendizagem? Esse questionamento traz à tona reflexões acerca das práxis (ação/reflexão) pedagógica no que tange ao fazer e como fazer, para que o entrave 
estabelecido no contexto atual da educação que é a aprendizagem, seja superado. Essa inquirição, dialoga diretamente com as experiências vivenciadas ao longo dos de vinte e cinco anos de regência, que deram margem a seguinte indagação. Assim, a partir do levantamento bibliográfico, o objetivo desse artigo é, apresentar uma breve contextualização das concepções de avaliação da aprendizagem.

\section{ASPECTOS HISTÓRICOS DA AVALIAÇÃO DA APRENDIZAGEM}

A abordagem de ensino tradicional é caracterizada por ser muito rígida e centrada no professor, sendo o mesmo o detentor da verdade pronta e acabada. Essa concepção de educação como um produto, ou seja, trata-se de transmissão de ideias selecionadas. O papel do professor é basicamente o de transmitir conteúdos predefinidos, o que ele passa é absoluto e inquestionável. A aprendizagem era medida pela reprodução dos conteúdos feitos pelos alunos. as aulas são expositivas e demonstrativas e se baseavam em quatro pilares: escutar, ler, decorar e repetir (BEHERNS, 1999).

Ainda nessa abordagem, a avaliação, por muito tempo, foi realizada visando a reprodução do conteúdo tradicional e disciplinar passado em sala de aula. Podendo ser feito através de exames, provas, teste e exercícios. Segundo Libâneo(1990), a avaliação da aprendizagem se dá pela verificação de curto e de longo prazo, tais como: interrogatórios orais, exercícios para casa, provas escritas, trabalhos etc.

Essa não é uma abordagem diferente do que se pratica hoje em dia nas escolas, onde o professor na sala ensina e o aluno finge que aprende. Onde a responsabilidade do fracasso ou sucesso é sempre do aluno. Observase então, que prática avaliativa adotada, na maioria das escolas, é de apenas atribuir nota ao aluno.

A História da avaliação de aprendizagem constitui-se em algo recente, quando nos referimos às práticas pedagógicas cotidianas a aos próprios documentos que norteiam o processo educativo brasileiro. No entanto, os atos de examinar e verificar aprendizagem percebe-se que essa história é mais longa, visto que nos remete a modelos de ensino escolares praticados desde o século XVI, com o nascimento da escola moderna, caracterizado pela representação social do professor como detentor do conhecimento e 
controlador do processo ensino e aprendizagem.

Nesse sentido, ela retratava as experiências vivenciadas pelos sujeitos, despertando o prazer para alguns e a humilhação para outros. Para compreender esse processo faz-se necessário retomar o seu caráter histórico, que se originou por volta do século XVII e tornou-se indissociável do ensino de massa que conhecemos desde o século XIX (ESTERBAN,1999).

Segundo Luckesi (2002) as primeiras práticas avaliativas surgiram na sociedade chinesa em 1.200 a.C. Seu objetivo inicial era o controle, tanto é que a nomenclatura utilizada nesse período era "exame". Cabe frisar, que não não aparece como uma espécie de instrumento educativo, mas no formato de manutenção social. Os primeiros a serem expostos foram os homens, na tentativa de alcançarem o serviço público.

O autor ainda aponta que a 'avaliação como sinônimo de provas e exames' é herança de 1599, trazida para o Brasil pelos Jesuítas, uma vez que enfatizava a memorização e dava especial importância à retórica e à redação. Esse ensino (Jesuítico) era caracterizado por sua postura tradicional com o foco no professor e levava o aluno a uma prática que o distanciava da convivência com a sociedade, no que se refere às práticas da vida cotidiana.

Entre os séculos XVII e XIX surgem as primeiras correntes que institucionalizaram os exames: as primeiras foram postas por Comenius que defendia o exame como um espaço de aprendizagem e não de verificação da aprendizagem. $\mathrm{O}$ exame, nesse sentido, era classificado como um instrumento aliado e precioso em relação à prática docente. Do outro lado, La Salle defendia o exame como supervisão permanente, na qual o aluno e era submetido a exclusivamente por exames, mensurando assim, seu conhecimento.

Ainda sim, ambas perspectivas impulsionaram os princípios da pedagogia do exame, que em linhas gerais tratavam da qualidade da educação, vista como um sistema eficiente que deveria atender as necessidades. Esse instrumento conseguia promover e certificar a aprendizagem dos educandos (LUCKESI, 2002).

A partir do século XX, a pedagogia do exame, assume o termo 'teste'. Nesse momento histórico, os testes eram aplicados exclusivamente para medir a inteligência humana, sendo possível, atribuir quociente intelectual (QI), 
levando em consideração a idade mental e idade cronológica do sujeito. Por muito tempo, esses eram classificados como instrumentos de caráter científico, sendo válidos e objetivos. Essa teoria foi de responsabilidade do pedagogo e psicólogo francês Alfred Binet. Segundo ele, objetivo dessa prática avaliativa tinha o fundamento de identificar as dificuldades de aprendizagem dos educandos, principalmente, na rede pública francesa no ano de 1905 (LUCKESI, 2002).

O termo "avaliação educacional ou avaliação da aprendizagem" foi proposto primeiramente por Ralph Tyler, educador norte-americano em 1934 conceituando deste modo a prática de diagnosticar 0 andamento da aprendizagem dos educandos na vida escolar. A partir daí vários fenômenos passaram a ser denominados de avaliação: o exame passou a ser chamado de avaliação, seleção passou a ser chamado de avaliação, nascendo assim a prática equivocada do que seja avaliação. Os termos- exames e avaliaçãoexpressam conceitos diferentes, ou seja a avaliação é um ato que não julga nem se classifica, e sim diagnóstica e intervém a favor da melhoria dos resultados do educando enquanto que o ato de examinar é excludente, seletivo, classificatório conduzindo assim a política da reprovação caminhando para o fracasso escolar (LUCKESI, 2005, p. 39-40)

\begin{abstract}
Avaliação da aprendizagem não é e não pode continuar, equivocadamente, sendo a tirana da prática educativa, que ameaça e submete a todos. Basta de confundir avaliação da aprendizagem com exames. A avaliação da aprendizagem, por ser avaliação, é amorosa, inclusiva, dinâmica e construtiva; diversa dos exames, que são classificatórios, seletivos, excludentes. A avaliação inclui, traz para dentro; os exames selecionam, excluem, marginalizam; por isso, dentro da atividade escolar, eles são usados indevidamente.
\end{abstract}

Nesse sentido, a avaliação é elemento integrante do processo ensinoaprendizagem e ganhou na atualidade espaço muito amplo nos processos de ensino. Requer preparo com componentes especializados e grande capacidade de observação dos profissionais envolvidos. Porém, ainda hoje, a avaliação da aprendizagem é vista por muitos como o ato de mensurar o conteúdo que foi aprendido pelo aluno em cada período escolar. Essa forma de avaliação quase sempre é aproveitada de forma qualitativa, sendo utilizada muitas vezes tendo a nota como objetivo maior e pouco para estabelecer uma qualidade do ensino obtido pelo educando. 
Abordagem Escolanovista, no século XIX na Europa e nos EUA, um movimento educacional que carregava como pilar principal de luta, a democratização do acesso ao ensino como forma de corrigir a injustiça social fixa-se na crença de que a educação é um processo interno e não externo e, portanto, deve partir das necessidades e interesses individuais. Aqui o aluno é o centro da educação, ou seja, o centro das atenções para o processo de ensino-aprendizagem. É um processo que acontece em conjunto alunoprofessor, buscando a aprendizagem. Facilita aos alunos o seu pleno desenvolvimento, o relacionamento interpessoal, a curiosidade, adaptação a novas situações (GONÇALVES; LARCHERT, 2011).

A escola é um clima favorável para o desenvolvimento, realização e autonomia do aluno. Enfatiza o ensino centrado no aluno visando uma formação para a democracia. Ainda segundo Gonçalves e Larchert (2011) nesta abordagem, a avaliação da aprendizagem teve que ser fluida e eficaz, na medida em que os esforços e os êxitos são reconhecidos pelo professor, ou seja, uma avaliação voltada para acolher e valorizar os avanços dos alunos, privilegiando-se mais a autoavaliação.

Abordagem Tecnicista aparece nos Estados Unidos na segunda metade do século XX e é introduzida no Brasil entre 1960 e 1970. Essa tendência, com base no positivismo, vê o aluno como um espectador frente à realidade objetiva, um aprendiz por meio do estímulo e reforço, exigindo respostas prontas e corretas.

O professor, nesse momento histórico, é o elo de ligação entre o aluno e o saber, transmite e reproduz o conhecimento. Segundo Libâneo (1990), o professor é apenas o elo entre a verdade científica e o aluno cabendo a ele a seguir competentemente os manuais já prescritos. Aqui a escola treina os alunos para a máquina do sistema social, sendo competentes para o trabalho, não sendo necessário estabelecer uma relação com o mundo do conhecimento, seus processos históricos e culturais, o que importa é a memorização mecânica.

$\mathrm{Na}$ abordagem Tecnicista, identifica-se $\mathrm{O}$ modelo tradicional de avaliação da aprendizagem, uma vez que ao longo da década de 60 a avaliação, tinha o objetivo de julgar a efetividade do processo de aprendizagem de visto numa perspectiva exclusiva de desempenho final. Assim, o ensino e a 
avaliação da aprendizagem estavam voltados para a produtividade dos alunos, que ocorre no final do processo para verificar se eles atingiram ou não os objetivos estabelecidos. O foco da avaliação não se centrava no sujeito que aprende nem nos seus mecanismos mentais e, sim, nos resultados já determinados.

Abordagem Interacionista deu-se no início do século XX. A abordagem interacionista concebe a aprendizagem como um fenômeno que se realiza na interação com o outro. O foco dessa abordagem de aprendizagem centrou-se no aluno, o professor assume o papel de orientador do processo ensino e aprendizagem. O erro do aluno deixa de ser motivo de punição, analise do erro constitui um novo ponto de partida para que o professor possa saber até que ponto o aluno aprendeu a matéria e assim possa replanejar suas aulas de modo a abordar o mesmo de conteúdo de uma forma mais criativa e dinâmica.

Neste sentido, avaliação deixa de ser uma atividade classificatória e passa a ser concebida como uma atividade permanente no trabalho do professor, acompanhando de perto o processo de ensino e de aprendizagem. (GONÇALVES; LARCHERT, 2011).

Contudo, a avaliação da aprendizagem torna-se objeto de pesquisa e ainda mais questionada a partir da década de 80 , sendo colocada em análise dos estudos de teóricos diversos como Perrenoud (1998), Luckesi (2000); Vasconcellos (1998), Zaballa (1998), Hoffman (2008). No entanto, essa concepção avaliativa trouxe para o contexto escolar uma dialética pedagógica diferenciada, visto que dentro dessa concepção cabe ao professor acompanhar o processo avaliativo, através de coletas e registros cuidadosos sobre os alunos para a partir deles tomar as decisões pedagógicas necessárias para retomar a construção da aprendizagem.

Para tanto, ao longo do tempo a escolaridade obrigatória foi norteada pelos princípios da avaliação excludente e classificatória, que no seu bojo explicita a passividade dos educandos frente à construção do conhecimento onde são comparados e depois classificados em virtude de uma norma de excelência, definida no absoluto ou encarnada pelo professor e pelos melhores alunos. Assim:

A avaliação, da maneira que vem acontecendo, é uma praga que contamina toda a relação pedagógica. O condicionamento do aluno em função da nota, por exemplo compromete muitas propostas de 
alteração da prática de construção do conhecimento em sala de aula. (VASCONCELOS, 1998, p.12-13,1998).

Nesse sentido, o papel político da avaliação consiste em desmitificar o "Statuo Quo" impregnado na sociedade, onde a "inclinação ideológica" visa que cada um se conforme com seu lugar na sociedade, pelo reconhecimento de sua desvalia, de sua incompetência. Essa visão ideológica é estarrecedora, pois se interioriza no sujeito sem que ele se dê conta, e, dessa forma, acaba levando-o a legitimação e colaboração do dominador.

Sabe-se que a avaliação está presente no cotidiano da vida humana. "Avaliar", "julgar", "comparar", "mensurar", "classificar", "medir" são atitudes que realizamos em nossas ações diárias. Mas, quando no referimos a avaliação da aprendizagem escolar, necessário se faz refletir nossas práticas pedagógicas e concepção sobre avaliação escolar. Segundo Villas-Boas (1998, p.21), as práticas avaliativas podem, pois, servir a manutenção ou a transformação social. Dessa forma, pensar avaliação escolar requer atitude e ação, visto que as práticas avaliativas permeiam todo processo pedagógico, constituindo-se em início, meio e fim, não acontece em momentos isolados.

Segundo, Caldeira (2000, p. 122):

\begin{abstract}
A avaliação escolar é um meio não um fim em si mesma; está delimitada por uma determinada teoria e por uma determinada prática pedagógica. Ela não ocorre num vazio conceitual, mas está dimensionada por um modelo teórico de sociedade, de homem, de educação e, consequentemente, de ensino e de aprendizagem, expresso na teoria e na prática pedagógica.
\end{abstract}

Assim, a avaliação escolar não é neutra, sua concepção nos faz entender que há intencionalidade política, pedagógica e epistemológica que norteia o processo ensino aprendizagem. Portanto, essa ideia corrobora com Perrenoud (1999) na qual afirma que a avaliação está no centro do sistema didático e do sistema de ensino.

Ainda nessa perspectiva, a própria etimologia da palavra avaliar, que vem do latim avalare, significa atribuir valor ao objeto em estudo assim, avaliar é atribuir juízo de valor sobre uma ação ou uma matéria. Agora se tratando de avaliar no processo de ensino e aprendizagem o seu significado, em grande parte da história educacional referiu-se ao ato de medir os conhecimentos adquiridos pelos alunos, ou seja, atribuir exclusivamente uma nota 
(GONÇALVES; LARCHERT, 2011)

Segundo Luckesi (2002), a avaliação da aprendizagem deve ser assumida com um instrumento que existe, para avaliar a qualidade da assimilação do conhecimento por parte do aluno e para compreender em que estágio da aprendizagem ele se encontra. Hoje em dia, alguns educadores modificaram sua percepção sobre o que é avaliar, pois passaram a perceber a amplitude do conhecimento do aluno no cotidiano e não apenas um momento único, além de perceber as peculiaridades de cada discente. Porém, a avaliação ainda se configura como a obtenção de um resultado objetivo, por meio de notas.

De acordo com os estudos de Bloom(1983), Hastings e Madaus (1971), no manual da Avaliação Formativa e Somativa, a avaliação do processo ensino-aprendizagem, apresenta três tipos de funções: diagnóstica(analítica), formativa(controladora) e somativa (classificatória).

O primeiro tipo é a avaliação diagnóstica, em linhas gerais, ocorre no início de um processo de aprendizagem e tem a função de obter informações sobre os conhecimentos dos educandos. O professor tem como principal objetivo verificar o conhecimento prévio de cada aluno, tendo como finalidade constatar os pré-requisitos necessários de conhecimento que o estudante possui para uma nova etapa de aprendizagem. Esta forma de avaliação pode ser utilizada antes e durante o processo de ensino-aprendizagem. Se realizada antes do processo, tem como finalidade sondar se o aluno apresenta os conhecimentos necessários para que a aprendizagem seja iniciada. Se ocorre durante o processo, será utilizada para identificar as causas das falhas da aprendizagem e possibilitar a sua possível correção. (GONÇALVES; LARCHERT, 2011).

Avaliação somativa é uma modalidade avaliativa pontual que ocorre ao fim de um processo educacional (ano, semestre, bimestre). É também conhecida como avaliação das aprendizagens. Está preocupada com os resultados das aprendizagens, sua principal característica é classificar o avaliado. Essa avaliação pode ser apresentada de várias formas: teste, prova, debates, dissertações etc. devendo ao aluno atingir uma determinada média anual para ser aprovado. Como desvantagens essa forma de avaliar eleva os níveis de estresse e ansiedade dos alunos. (GONÇALVES; LARCHERT, 2011). 
Avaliação formativa, sendo o ideal, é aquela que tem como função controlar, devendo ser realizada durante todo o período letivo. Dita também processual a avaliação formativa permite ao professor detectar e identificar deficiências na forma de ensinar. É a partir da avaliação formativa que o aluno toma conhecimento dos seus erros e acertos. A avaliação formativa é realizada ao longo do processo, é contínua, e dá parâmetros ao professor para verificar se os objetivos foram alcançados, podendo interferir no que pode estar comprometendo a aprendizagem (GONÇALVES; LARCHERT, 2011).

Cada um dos tipos de avaliação tem uma função específica que pode ser usada em diferentes momentos do processo avaliativo. Suas funções dependem da forma de uso e dos objetivos que se busca atingir. Nesse sentido, percebe-se que a pratica avaliativa favorável à aprendizagem, demanda mudanças de postura do docente, visto que necessita transcender a gênese histórica, as armadilhas, as injustiças, os escamoteamento presentes na lógica avaliativa classificatória para aprender a internalizar os pressupostos que regulam a aprendizagem, tomando decisões de posturas e intervenções pedagógicas que favoreçam a aprendizagem.

Mas, nesse caso, será necessário que o docente transcenda a dimensão da sua própria realidade pedagógica e conceitual. Todavia, isso requer mexer com valores, concepções enraizadas, pressupostos teóricos, possibilidades, limites, certezas, incertezas, visão de mundo, zona de conforto, enfim requer construir novas concepções teóricas e práticas pedagógicas dentro e fora do âmbito da sala de aula (LUCKESI, 2002).

Ė importante lembrar que transformar realidade da avaliação da aprendizagem exige mediação teórica. Então, mexer com os pressupostos supracitados é preciso arcabouços teóricos que possibilitem e orientem a intervenção do sujeito na prática. Então, mudança de prática e transformação de realidade perpassa pelo querer, saber e condições do sujeito.

Assim sendo, trazer à tona a temática de avaliação, requer mexer com toda a estrutura da escola, é transcender crenças e valores, é superar concepções, é buscar alternativas que privilegie a aprendizagem e supere a simples lógica do reprovar e aprovar sem oportunizar ao sujeito adquirir habilidades e competências que o insira no contexto social e o instrumentalize para Ihe dar com as adversidades e diversidades do mundo contemporâneo 
(GONÇALVES; LARCHERT, 2011)..

Independente do tipo de avaliação, é importante considerar que a espécie humana em sua essência "julga", "mensura", "classifica", "inclui", "exclui", "seleciona", "classifica", "acolhe", "integra", ou seja, a todo momento exerce a prática do avaliar. No entanto, quando nos referimos à avaliação da aprendizagem no contexto escolar esses verbos de uma forma ou de outra estão presentes. Mas avaliação da aprendizagem requer práticas formalmente organizadas e sistematizadas que implicam na interação dos sujeitos que compõem o processo aprendizagem, no intuito de promover a aprendizagem. Perrenoud (1998) afirma que a avaliação não é fim em si.

È uma engrenagem no funcionamento didático e, mais globalmente, na seleção e na orientação escolares. A partir dessa perspectiva, pode-se afirmar que a avaliação de aprendizagem não acontece em momentos estanques do trabalho pedagógico. Ela inicia, premeia e conclui todo o processo. Então, encontra-se no centro das ações pedagógicas e escolares (GONÇALVES; LARCHERT, 2011).

\section{AVALIAÇÃO FORMATIVA: CONCEPÇÃO CONTÍNUA DO ATO DE AVALIAR}

A avaliação da aprendizagem estabelece-se como condição necessária para tornar o processo pedagógico claro, destinando-se a melhoria da aprendizagem dos alunos. De acordo como Perrenoud (1998, p. 15) a avaliação não é, em princípio, um objetivo em si, mas um meio de verificar se os alunos adquiriram os conhecimentos visados. Assim, para além da reprovação ou aprovação a avaliação está a serviço da aprendizagem, constituindo-se em instrumento de mediação e regulação da aprendizagem dos alunos.

Atualmente, o professor no seu cotidiano escolar depara-se com uma série de dificuldades que impossibilitam a construção de uma Educação de qualidade. Como a avaliação da aprendizagem está no centro das ações pedagógicas, mobilizando-as para cumprir a função social da escola que é a construção do conhecimento, pensar em avaliação de aprendizagem é tomar decisões que possibilitem a melhoria de ensino, e consequentemente, melhoria da aprendizagem dos alunos. 
Então, a avaliação da aprendizagem torna-se o centro da tomada de decisão do trabalho pedagógico, direcionando o professor a construir um caminhar avaliativo e metodológico destinado à melhoria da aprendizagem dos alunos. Ainda sobre essa perspectiva, Luckesi (2011) define a avaliação da aprendizagem como ato amoroso, no sentido de que a avaliação, por si é um ato acolhedor, integrativo, inclusivo. Nesse sentido ela deve superar a lógica do aprovar ou reprovar, ou seja, sair do plano do julgamento que carrega no seu processo a exclusão, e adquirir um caráter diagnóstico e acolhedor, centrando-se na inclusão, isto é, na tomada de decisão, ou seja, direcionar o trabalho pedagógico no sentido da obtenção de resultados que possibilitem a aprendizagem dos alunos.

Corroborando a essa visão Hoffmann (2008, p. 17), a avaliação é:

[...] uma ação ampla que abrange o cotidiano do fazer pedagógico e cuja energia faz pulsar o planejamento, a proposta pedagógica e a relação entre todos os elementos da ação educativa. Basta pensar que avaliar é agir com base na compreensão do outro, para se entender que ela nutre de forma vigorosa todo o trabalho educativo

Dessa forma, a avaliação da aprendizagem constitui-se no meio em que o professor pode adquirir informações sobre os avanços e dificuldades dos alunos, constituindo-se em um elemento impulsionador do processo ensino aprendizagem, na medida em que oferece ao professor mediar, planejar e replanejar suas ações pedagógicas, no intuito de possibilitar ao aluno desenvolver habilidades e competências que os permitam prosseguir no processo ensino aprendizagem com êxito.

Comungando com essa lógica, Vasconcellos (1998, p. 36) afirma que a "avaliação é um processo abrangente da existência humana que implica reflexão sobre a prática, no sentido de diagnosticar seus avanços e dificuldades e, a partir dos resultados, planejar tomadas de decisão sobre as atividades didáticas posteriores". Assim, a avaliação é um processo contínuo e permanente que possibilita ao professor acompanhar o aluno, (re) construindo percursos e (re) fazendo práticas, a fim de tornar o processo avaliativo instrumento facilitador da aprendizagem.

Seguindo a mesma concepção, Hoffmann (2001, p. 52) aponta "a ação avaliativa como interpretação cuidadosa e abrangente das respostas do aluno frente a qualquer situação de aprendizagem, sendo necessário entendê-la 
como acompanhamento de uma trajetória". Então, podemos afirmar que superar a lógica excludente e classificatória da avaliação requer entender que a avaliação da aprendizagem está para além da lógica da reprovação e aprovação, ela existe para regular a aprendizagem e tornar os atores do processo avaliativo focados nos processos de cognição, baseando o processo avaliativo em três pilares: ação, reflexão e ação.

. De acordo com Zabala (1998, p. 2010)

Dificilmente podemos conceber a avaliação como formativa se não nos desfizer de algumas maneiras de fazer que impedem mudar as relações entre alunos e professor. Conseguir um clima de respeito mútuo, de colaboração, de compromisso com um objetivo comum é condição indispensável para que a atuação docente possa se adequar às necessidades de uma formação que leve em conta as possibilidades reais de cada aluno e o desenvolvimento de todas as capacidades. [...] um clima de cooperação e cumplicidade, é a melhor maneira de que dispomos para realizar uma avaliação que pretende ser formativa.

Dessa forma, conceber a concepção avaliativa formativa requer que o professor descontrua o autoritarismo e a lógica quantitativa da avaliação e construía o processo ensino aprendizagem numa perspectiva de cumplicidade e confiança, baseado na relação de ajuda mútua entre professor e aluno e que a mediação e intervenção seja o ponto de congruência para a regulação e construção da aprendizagem, tornando o processo avaliativo mais acolhedor e integrativo.

Ainda nessa perspectiva, Perrenoud (1998) pontua que a regulação das aprendizagens é a característica básica da avaliação formativa, exigindo do professor e do aluno uma participação ativa no processo, isto é, ao professor cabe um olhar cuidadoso e diferenciado sob o sujeito avaliado, compreender seus funcionamentos, para ajustar de forma sistemática e individualizada suas intervenções pedagógicas e promover situações didáticas que favoreçam a regulação da aprendizagem. O aluno deve tomar consciência do seu processo e sentir-se responsável por sua própria aprendizagem

Para Perrenoud (1998, p. 90):

regulação dos processos de aprendizagem, em sentido bastante amplo, o conjunto das operações metacognitivas do sujeito e de suas interações como o meio que modificam seus processos de aprendizagem no sentido de um objetivo definido de domínio."

Assim, compreender a avaliação formativa consiste em entender que ela 
deve oportunizar o educando crescer e se desenvolver de forma significativa, para tanto, deve-se ressaltar as três etapas, que evidenciam a regulação das aprendizagens numa perspectiva formativa, que são: retroativas, interativas e proativas. Cabe salientar, que as três etapas podem inter-relacionar-se. Sendo assim, a retroativa não se limita apenas a uma remediação, mas, podem partir de elementos anteriores, posteriores ou até mesmo durante a trajetória da aprendizagem. A regulação proativa consiste no movimento de engajar o aluno em atividades ou situações de aprendizagem. Antes de iniciar o ensino faz-se necessário considerar que o aluno já sabe sobre o mesmo, quais são suas disposições, ânimo e seus recursos. Já a regulação interativa pode ser levada a uma regulação proativa ou retroativa e reencontra-se em uma lógica da antecipação da remediação (PERRENOUD, 1998).

Assim, a avaliação formativa é feita ao longo do processo de modo contínuo, com o intuito de verificar se os alunos estão atingindo os objetivos previstos, isto é, quais os resultados alcançados durante o desenvolvimento das atividades. Com os resultados desta avaliação, busca-se adequar ou reprogramar o processo, visando condições de melhoria de ensino e de aprendizagem.

\section{CONSIDERAÇÕES FINAIS}

A avaliação da aprendizagem, por muito tempo, imperou a concepção de estrutura organizacional padronizada, como se os sujeitos fossem iguais, não oportunizando uma regulação individualizada. No entanto, esses entraves não invalidam a busca por um sistema avaliativo mais justo, pois para mudarmos a estrutura organizacional da escola, é preciso mudar nossas concepções, no que tange, ao processo ensino-aprendizagem e avaliativo, tornando-os legítimos.

Por outro lado, esse estudo, defende que é necessário se faz perceber a verdadeira função da escola e da avaliação da aprendizagem, q é oferecer a todos o acesso significativo no processo de ensino e aprendizagem, permitindo entre outras coisas, a interação dos novos sujeitos com o conhecimento acumulado da humanidade, de forma organizada, sistematizada, coletiva sobretudo, significativa.

Pensar e trazer à tona das concepções de avaliação da aprendizagem, 
no contexto escolar e nas ações pedagógicas cotidianas do professor em sala de aula, requer refletir o verdadeiro papel desta na prática docente. Nesse contexto, avaliar vai muito além da realização das provas e testes, pois é um processo contínuo e que ocorre dia após dia, diagnosticando e intervindo na melhoria dos resultados do educando, buscando o melhor e mais satisfatório estado do que está sendo avaliado. A avaliação é um ato que inclui o educando, acontecendo de forma dinâmica e construtiva, funcionando como um elemento de integração e motivação para o processo de ensinoaprendizagem.

Sendo assim, avaliar não pode ter uma concepção mecânica pautada por diversificação de atividades que irão consolidar-se em uma nota, deve trazer no seu bojo momentos de parada para análise e do caminhar do aluno no curso da aprendizagem. Então o processo avaliativo deve ser pautado na comunicação direta entre professor e aluno com intuito de superar as dificuldades.

Em suma, a escola e os educadores devem assumir a avaliação na concepção formativa como uma ação pedagógica continua, progressiva, sistemática, flexível, orientadora, personalizada, que respeita o ritmo de aprendizagem de cada sujeito, voltada para as aprendizagens. Mas, o movimento pedagógico voltado para essa concepção avaliativa requer romper paradigmas e intervenções pedagógicas focadas no processo individual de cada sujeito, reconhecendo avanços e dificuldades para regulação das aprendizagens.

Para tanto, é imprescindível buscar alternativas que viabilizem um sistema avaliativo, favorecendo a inclusão do educando e do educador, como sujeitos do processo de formação, oportunizando a regulação das aprendizagens, concretizando o propósito da educação de qualidade que é aprender. Assim, as mudanças devem corroborar com um sistema avaliativo formativo, que por sua vez, requer uma transformação do método de ensino, gestão de aula, mudança tempo/espaço dentro e fora da sala de aula, organização de turmas, dentre outras.

\section{REFERÊNCIAS}

AQUINO, J. L. F.; NETO, A. L. C. A Avaliação da Aprendizagem como um ato 
amoroso: o que o professor prática? Educação em Revista, Belo Horizonte, V. 25, n.02, p. 223-240, ago. 2009.

BEHRENS, M. A. O paradigma emergente e a prática pedagógica. Curitiba: Champagnat, $1999.131 \mathrm{p}$.

BOAVENTURA, E. M. Metodologia da pesquisa: monografia dissertação, tese. São Paulo: Atlas, 2004.

BLOOM, B. S. et. al. Manual de avaliação formativa e somativa do aprendizado escolar. São Paulo: Livraria Pioneira Editora, 1983.

BRASIL, Lei de Diretrizes e B. Lei $n^{\circ}$ 9.394/96, de 20 de dezembro de 1996. BRASIL, Ministério da Educação e do Desporto, Secretaria de Educação Fundamental. 1996

BRASIL. Constituição (1988). Constituição da Republica Federativa do Brasil. Brasília,DF: Senado Federal, 1988

CALDEIRA, A. M. S. Avaliação e processo de ensino aprendizagem. Presença Pedagógica, Belo Horizonte, v. 3, pa.53-61, set./out. 1997.

CALDEIRA, A. M. S. Ressignificando a avaliação escolar. In. Comissão Permanente de Avaliação Institucional, UFMG-PAIUB. Belo Horizonte: PROGRAD/UFMG, 2000. P.122-129 (Caderno de Avaliação, 3).

CERVO, A. L.; BERVIAN, P. A. Metodologia cientifica: para uso dos estudantes universitários. 3 ed. São Paulo: McGraw-Hill do Brasil, 1983.

CHUEIRI, M. S. F. Concepções sobre a Avaliação Escolar. Abave. Estudos em Avaliação Educacional, v. 19, n. 39, jan./abril. 2008.

CERVO, A. L.; BERVIAN, P. A. Metodologia cientifica: para uso dos estudantes universitários. 3 ed. São Paulo: McGraw-Hill do Brasil, 1983.

DOMINGOS, F. Para uma teoria da avaliação formativa. Revista Portuguesa de Educação, v. 19, nº 02, P. 21-50, Porto, 2006.

ESTEBAN, M. T. (org.) Avaliação: Uma Prática em busca de novos sentidos. Rio de Janeiro. DFSA, 1999.

FERNANDES, C. A. Análise do discurso: Reflexões introdutórias. Florianópolis. Rio de Janeiro: Vozes, 2006.

GONÇALVES, A. L.; LARCHERT, J. M. Avaliação da aprendizagem: Pedagogia. Módulo 4, volume 6- EAD/Elaboração de conteúdo. Ilhéus-BA: Editus, 2011.

HOFMAN, J. Avaliar para promover: as setas do caminho. Porto Alegre: Mediação, 2001. 
HOFMAN, J. Pontos e contrapontos do pensar ao agir em avaliação. Porto Alegre: Mediação, 2007

HOFMAN, J. Avaliar para promover: as setas do caminho. Porto Alegre: Mediação, 2008.

LEITE, S; KAGER, S. Efeitos aversivos das práticas de avaliação da aprendizagem escolar. Ensaio: Avaliação e Políticas Públicas em Educação. Rio de Janeiro, v. 17, n. 62, jan/mar 2009.

LIBÂNEO, J. C. Democratização da escola pública. A pedagogia criticosocial dos conteúdos, São Paulo: Edições Loyola, 1990.

LUCKESI, C. C. Primeira Constatação: a escola pratica mais exames que avaliação. In: Avaliação da aprendizagem componente do ato pedagógico. São Paulo: Cortez, 2011.

LUCKESI, C. C. Avaliação da Aprendizagem escolar: Estudos e preposições. São Paulo, Ed Cotez. 2005

LUCKESI, C. C. Avaliação da aprendizagem na escola e a questão das representações sociais EccoS. Revista Científica, vol. 4, núm. 2, dezembro, 2002

LUCKESI, C. C. Avaliação da aprendizagem escolar. 10. ed. São Paulo: Cortez, 2002.

MARCONI, M. A.; LAKATOS, E. M. Fundamentos de metodologia científica. São Paulo: Atlas 2003.

MENDES, O. M. Avaliação formativa no ensino superior: reflexões e alternativas possíveis. In: VEIGA, I. P. A e NAVES, M. L.P.(orgs). Currículo e avaliação na educação superior. Araraquara-SP: Junqueira \& Marin,2005.

PERRENOUD, P. Avaliação da excelência à regulação das aprendizagens entre duas lógicas. Porto Alegre: Artmed, 1999.

PERRENOUD, P. Formação em avaliação entre idealismo ingênuo e realismo conservador. In: Práticas pedagógicas, profissão docente e formação: perspectiva sociológica. Lisboa: Dom Quixote, 1993, p. 155-170.

PERRENOUD, P. Construir as competências desde a escola. Porto Alegre: Artes Médicas Sul, 1999.

SEVERINO, A. J. Metodologia do trabalho científico. 23. ed.rev. e atual. São Paulo: Cortez,2007.

SPNILLO, A. G. Bases Construtivista da Avaliação: contribuição da Psicologia cognitiva (texto). Universidade Federal de Pernambuco, 
departamento de Psicologia - Mestrado em Psicologia, 1989.

TYLER, R. Princípios básicos de currículo e ensino. Porto Alegre: Globo, 1981.

VASCONCELLOS, C. S. Construção do Conhecimento em sala de aula. 10. ed., São Paulo: Libertad, 2000.

VASCONCELLOS, C. S. Planejamento Projeto de Ensino-Aprendizagem e Projeto Político-Pedagógico. 7 ed. São Paulo: Libertad, 2000.

VASCONCELLOS, C. S. Formação didática do educador contemporâneo: desafios e perspectivas. In: UNIVERSIDADE ESTADUAL PAULISTA. Prograd. Caderno de Formação: formação de professores didática geral. São Paulo: Cultura Acadêmica, 2011

VASCONCELLOS, C. S. Superação da lógica classificatória e excludente da avaliação. 2.ed., São Paulo: Libertad, 1998.

VASCONCELLOS, C. S. Resgate do professor como sujeito de transformação. 8. ed. São Paulo: Libertad, 2001.

VILLAS-BOAS, B M. F. As práticas avaliativas e a organização do trabalho pedagógico. Tese de Doutorado, Campinas, Faculdade de Educação Campinas, 1993.

VILLAS-BOAS, B M. F. Benigna M. de Freitas. Planejamento da avaliação escolar. Pró-posições, , nov. 1998.

ZABALA, A. A avaliação. In. A prática educativa: como ensinar. Trad. Ernani F. Rosa. Porto Alegre. Artmed, 1998 